Research Article

\title{
Study on Seismic Behavior of Steel Frame-Steel Shear Wall with Assembled Two-Side Connections
}

\author{
Yuben Zhang ${ }^{1}{ }^{1}$ and Xun Zhan ${ }^{2}$ \\ ${ }^{1}$ Zhejiang Industry Polytechnic College, Shaoxing 312000, China \\ ${ }^{2}$ Tongji University, Shanghai 200092, China \\ Correspondence should be addressed to Yuben Zhang; zhangyuben@zjipc.com
}

Received 7 May 2019; Revised 21 October 2019; Accepted 30 October 2019; Published 18 December 2019

Academic Editor: Miguel Castro

Copyright ( 2019 Yuben Zhang and Xun Zhan. This is an open access article distributed under the Creative Commons Attribution License, which permits unrestricted use, distribution, and reproduction in any medium, provided the original work is properly cited.

\begin{abstract}
Low-cycle reciprocating loading tests were carried out on a steel frame with prefabricated beam-only connected steel plate shear wall (specimen A) and a steel frame with welded beam-only connected steel plate shear wall (specimen B). The seismic performance of the two different types of steel frame-steel plate shear wall specimens was studied and the failure modes, hysteresis curve, skeleton curve, and seismic performance index, etc of two groups of specimens were obtained, together with the studies of failure characteristics, ductility, energy dissipation, and stiffness degradation of the two specimens. The results showed that the assembled steel frame-steel plate shear wall with connection joints of steel shear wall with discontinuous cover plate connected on both sides (DCPC) have good seismic performance. On the basis of no loss of seismic performance, DCPC joints can provide better energy dissipation capacity than traditional welded steel plate shear wall structures and ensure the good postearthquake repair function.
\end{abstract}

\section{Introduction}

Assembled steel structure is made of factory-processed modules spliced by field bolts, and it has the advantages of fast construction speed, good seismic performance, and easy quality assurance [1]. The development of assembled steel structure buildings can effectively resolve the excess capacity of iron and steel and make the construction industry return to industrialization [2]. As a new type of lateral resistance structure system, steel plate shear wall can bear most of the lateral loads in the structure, improve the initial lateral stiffness and horizontal bearing capacity of the structure, and act as the first line of defence before the main frame is destroyed so as to reduce the damage degree of the main frame and improve the collapse resistance of the structure $[3,4]$. It consists of embedded steel plate and edge member, in which the embedded steel plate can be connected with the edge member by bolting or welding. In order to make the steel plate shear wall system more suitable for the fabricated high-rise steel structure system, it is very important to study the influence of the fabricated connection form of the steel plate shear wall-embedded wall panel and the edge member on the lateral resistance of the structure.

In the existing engineering, the connection mode of quadrilateral welding is widely used [5], which leads to problems such as excessive welding quantity, difficult to guarantee the quality of welding seam, high cost of the structure, and long time limit. The bolted steel plate shear wall is mainly used in the structural test [6-10], and its purpose is to facilitate the connection of the test device and the repeated use of some components, but in the finite element numerical analysis, welding is still used to simulate the connection between the wallboard and the frame. The existing bolted joints are densely arranged and require highprocessing accuracy, which not only makes the practical difficulty of the bolted joints increase greatly, but also does not meet the energy-saving and high-efficiency characteristics of the assembly structure. Therefore, while guaranteeing the transmission performance, it is necessary to effectively reduce the number of bolts and avoid and prevent 
the impact of processing errors on the structure to realize the assembly of the steel plate shear wall.

Rong and Rusli $[11,12]$ analyzed and studied the influence of the connection mode between the embedded wallboard and the surrounding frame on the mechanical properties of the steel plate shear wall system and proposed that when the embedded wallboard is connected with the surrounding frame, the action of the steel plate on the frame column may lead to premature failure of the frame column; the steel plate shear wall connected only with the frame beam can avoid premature failure of the column. The use of steel plate shear walls connected on both sides can effectively reduce the number of connecting bolts, facilitate structural opening, and stiffness adjustment and avoid the adverse effects of buckling of steel plate shear walls on columns. Considering the characteristics of the assembled steel structure and steel plate shear wall system, a new type of discontinuous cover-plate shear wall joint (DCPC) is proposed, which is suitable for assembling high-rise steel structure. Low cyclic loading tests are carried out on one specimen of the welded steel frame-steel plate shear wall on both sides and one specimen of the steel frame-steel plate shear wall with DCPC on both sides.

\section{Design Principle, Construction, and Characteristics of DCPC Node}

The purpose of this joint is to effectively connect the embedded wallboard with the frame beam by using highstrength bolts. The design principle of joints is to avoid sliding between the embedded wallboard and the connecting plate. Therefore, the maximum shear force that a single highstrength bolt can bear should be guaranteed not less than the ultimate tensile strength of the tension band it shares. The advantage of this joint is that it can not only ensure the load transfer performance of the joint and give full play to the good lateral resistance of the steel plate shear wall, but also effectively reduce the accumulated error between the holes and is easy to assemble. DCPC can not only increase the number of effective friction surfaces and critical friction, but also avoid the phenomenon of the "unbutton."

As shown in Figure 1, the joint structure is characterized by connecting thin steel plate shear walls at both ends to facilitate structural opening and stiffness adjustment, avoiding adverse effects of buckling of steel plate shear walls on columns and opening large bolt holes in embedded steel plates and flanges of beams to increase the allowable value of processing cumulative errors and facilitate assembly, reduce the size of a single connector, reduce the cumulative error value that may be caused, and improve the allowable value of machining accuracy of components.

The arrangement of the embedded wall panel clamped by the bottom plate and the cover plate not only increases the friction surface between the wall panel and the connecting piece, but also effectively increases the critical friction and controls the bolt slip, and the out-of-plane warping force caused by buckling of the steel plate shear wall in the joint area is well avoided; even after the bolt hole is deformed, the connecting bolt will not collapse, so as to prevent the bolt from being released one by one from the outside to the inside. The connecting base plate and frame beam are welded and stiffeners are set to ensure the strength of the joint area, so that the connecting base plate and cover plate are free of residual deformation after the structure earthquake, which is convenient for the repair and replacement of the embedded steel plate after the earthquake.

\section{Testing Situation}

3.1. Specimen Design. Two single span two-story specimens ( $1 / 3$ scale) are designed to simulate the bottom two stories of the actual steel frame-steel plate shear wall structure. The two specimens are welded steel frame-steel plate shear wall specimens on both sides (B) and connected steel frame-steel plate shear wall specimens with DCPC on both sides (A). The specimens consist of three parts: hollow seamless square steel tube column, H-shaped steel beam, and steel plate shear wall. The dimensions of the square steel tube flange column and $\mathrm{H}$-shaped steel beam of the two groups of specimens are the same, and the thickness of the inner wall plate of the steel plate shear wall is $4 \mathrm{~mm}$. Because the steel plate shear walls are arranged on both sides of the middle beam, the middle beam is always alternately deformed in the equilibrium position due to the alternating influence of the tension bands on both sides during the reciprocating loading process. However, the roof beam is only affected by one side of the steel plate shear wall and the residual deformation cannot be restored. In order to avoid the failure of the test due to the premature failure of the roof beam, the section of the roof beam is larger [13]. The cross-sectional dimensions of the frame and inner steel plate are shown in Table 1, steel is $\mathrm{Q} 235 \mathrm{~B}$, and the test results of mechanical properties are shown in Table 2.

The processing diagram of specimen $\mathrm{A}$ is shown in Figure 2(a), the outer frame is machined in the factory, in which the flange of the frame beam is opened with large holes and welded with the connecting bottom plate, and the beam-column joints are welded. According to Figure 3(f), the connecting cover plate is machined and large bolt holes are opened on the embedded steel plate, and then all the components are shipped to the laboratory for assembly, as shown in Figure 2(b). The wall plate is connected by 10.9 grade M24 friction-type high-strength bolts, while the cover plate is connected with the beam by 10.9 grade M20 frictiontype high-strength bolts.

In specimen $\mathrm{B}$, the steel plate shear wall is connected with the frame beam by traditional fishtail plate welding and only the bottom of the specimen is connected with the ground beam by DCPC. By comparing the test results, the influence of the assembled joints and the traditional welded joints on the hysteretic behavior of the steel frame-steel plate shear wall is studied. Detailed processing drawings of components and beams are shown in Figure 3.

\subsection{Test Device}

3.2.1. Layout of Measuring Points. Two tension line displacement meters and three displacement percentile meters 


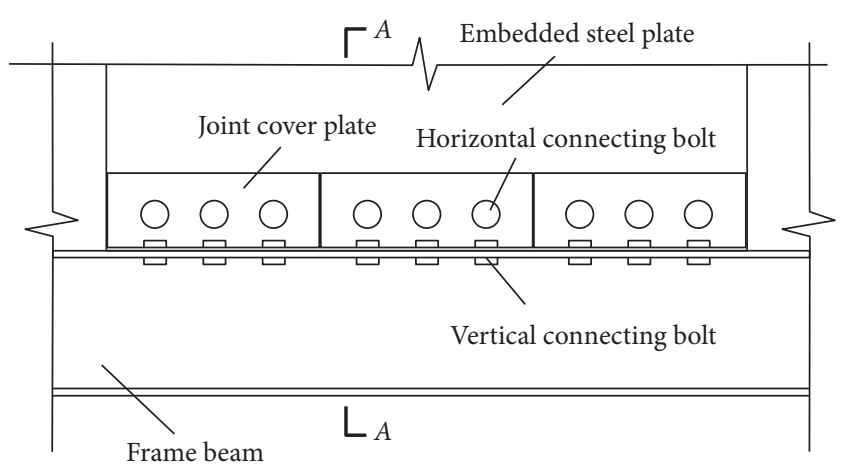

(a)

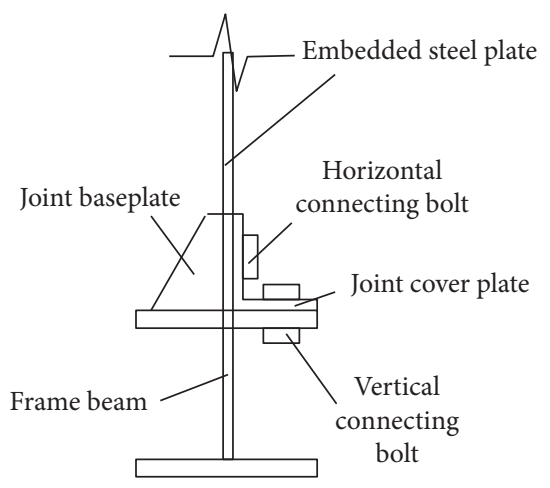

(c)

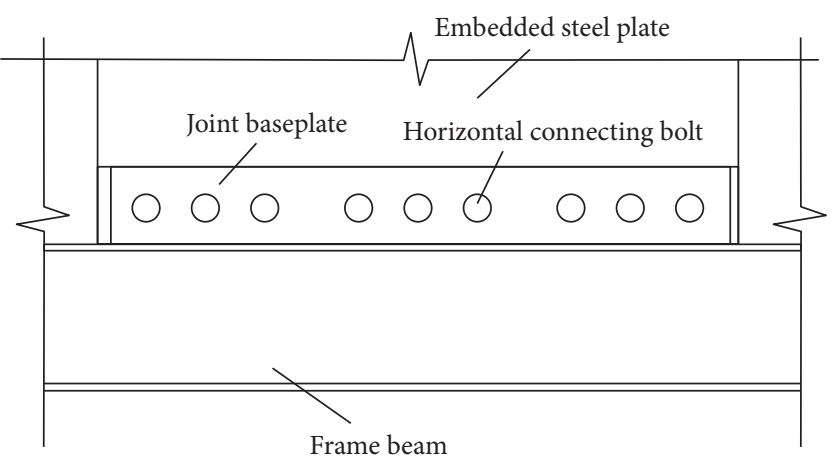

(b)

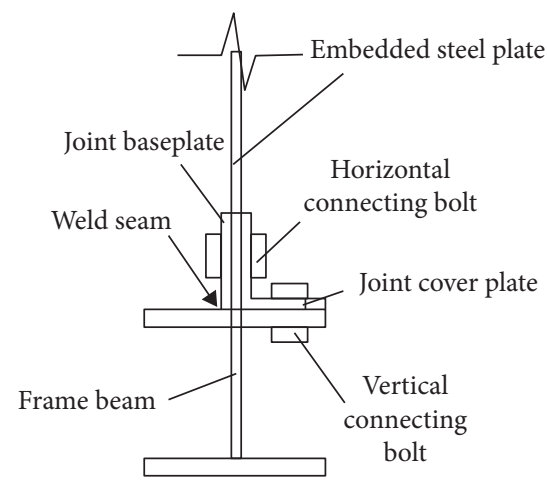

(d)

FIGURE 1: Layout of DCPC. (a) Structural map of discontinuous cover plate. (b) Structural map of baseplate. (c) Structural map of the side (d) A-A profile.

TABLE 1: Specific dimensions of specimens $(\mathrm{mm})$.

\begin{tabular}{lcccc}
\hline $\begin{array}{l}\text { Specimen } \\
\text { number }\end{array}$ & $\begin{array}{c}\text { Square steel string } \\
D \times t_{\mathrm{c}}\end{array}$ & $\begin{array}{c}\text { First floor of steel girder } \\
h_{\mathrm{b}} \times b_{\mathrm{f}} \times t_{\mathrm{w}} \times t_{\mathrm{f}}\end{array}$ & $\begin{array}{c}\text { Second floor of steel girder } \\
h_{\mathrm{b}} \times b_{\mathrm{f}} \times t_{\mathrm{w}} \times t_{\mathrm{f}}\end{array}$ & $\begin{array}{c}\text { Embedded wall panels } \\
t \times W \times H\end{array}$ \\
\hline A & $200 \times 12$ & $200 \times 200 \times 8 \times 12$ & $300 \times 200 \times 8 \times 12$ & $4 \times 900 \times 1190$ \\
B & $200 \times 12$ & $200 \times 200 \times 8 \times 12$ & $300 \times 200 \times 8 \times 12$ & $4 \times 900 \times 1190$ \\
\hline
\end{tabular}

TABLE 2: Mechanical properties of steel.

\begin{tabular}{lcccc}
\hline Thickness $/ \mathrm{mm}$ & Yield strength $\left(\mathrm{N} / \mathrm{mm}^{2}\right)$ & Tensile strength $\left(\mathrm{N} / \mathrm{mm}^{2}\right)$ & Elongation $(\%)$ & Elastic modulus $\left(\times 10^{4} \mathrm{~N} / \mathrm{mm}^{2}\right)$ \\
\hline 4 & 286 & 440 & 25.9 & 20 \\
8 & 276 & 428 & 25.2 & 20.5 \\
10 & 285 & 425 & 31.9 & 19.6 \\
12 & 267 & 429 & 29.8 & 20 \\
\hline
\end{tabular}

were set up in the experiment. Three displacement percentile meters are mainly used to measure the relative displacement between the bottom of the column and the ground beam and the absolute displacement of the ground beam. One stay wire displacement meter is set at the beam end of each floor to measure the displacement of the beam end. The displacement reading at the top beam is taken as the control index of the specimen loading. A displacement dial indicator is set at the back side of the specimen to measure the out-of-plane deformation of the joint area cover plate. In order to facilitate comparative analysis, the two components adopt basically the same strain gauge layout scheme. The only difference is that the specimen A also arranges strain gauges on the connecting cover of the wall-slab joint area, while the specimen B does not arrange strain gauges in the joint area. The layout of displacement gauge and strain gauge points is shown in Figure 4. The axial force on the top of the column and the reciprocating load on the end of the beam are output by the pressure sensor installed on the jack.

3.2.2. Loading Device. In order to ensure that the two floors of the specimens are at the same shear level, a $200 \mathrm{t}$ MTS electrohydraulic servo programmable actuator is used to exert low-cycle reciprocating load at one end of the top beam of the frame. Two compression beams are used to suppress 


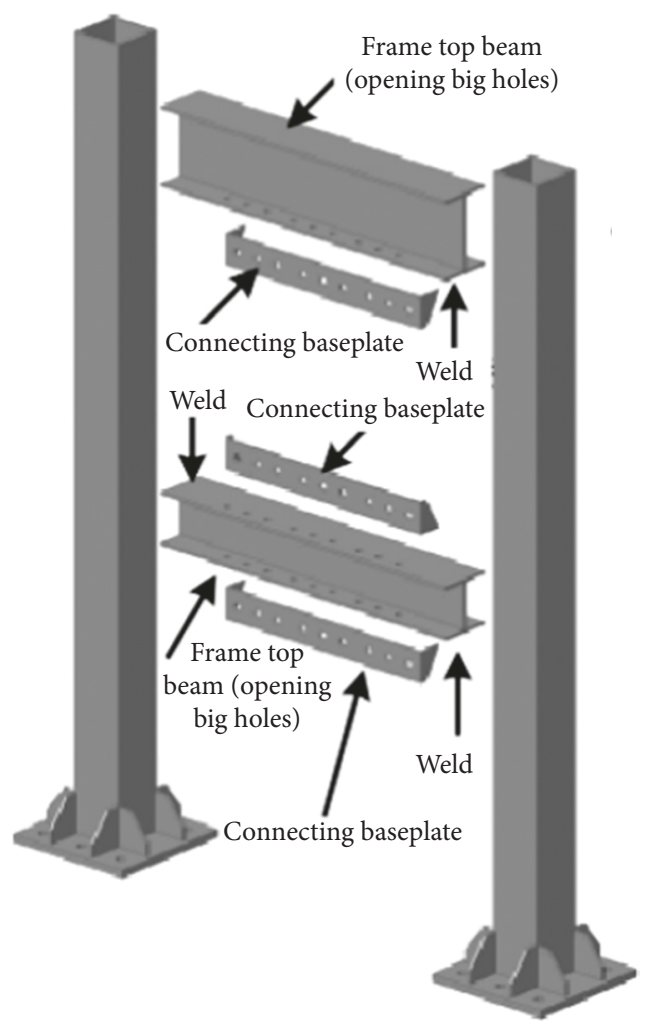

(a)

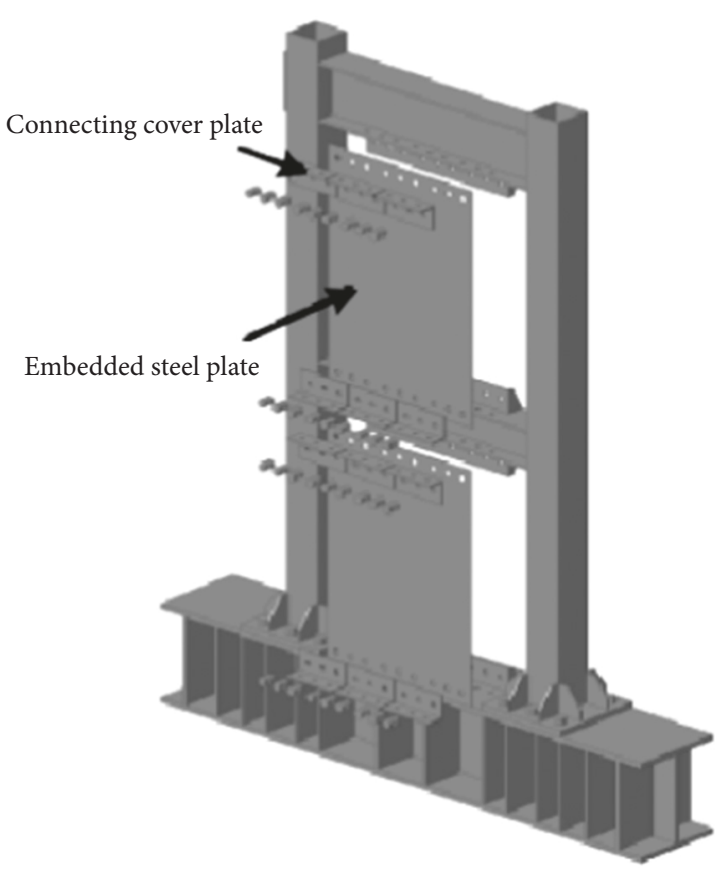

(b)

FIgURE 2: Schematic diagram of manufacture and installation for specimen A. (a) Outer frame drawing. (b) On-site assembly drawings.

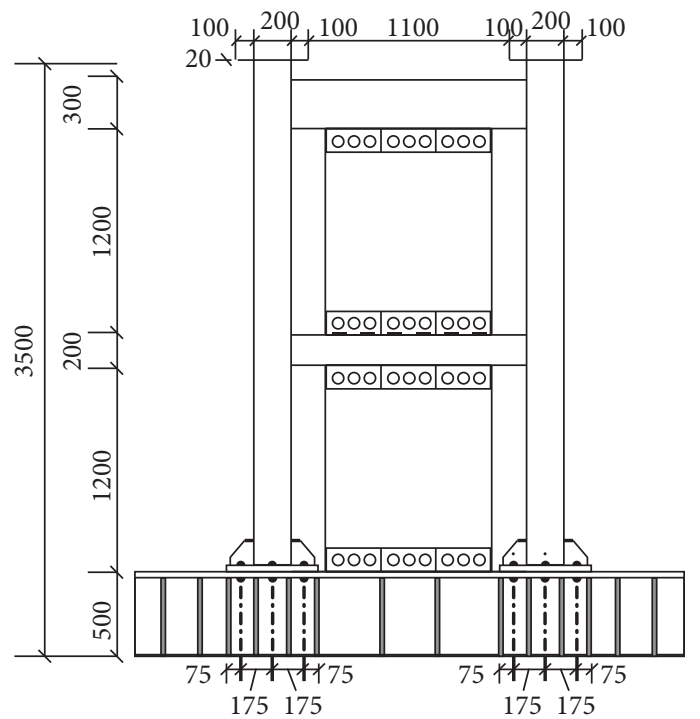

(a)

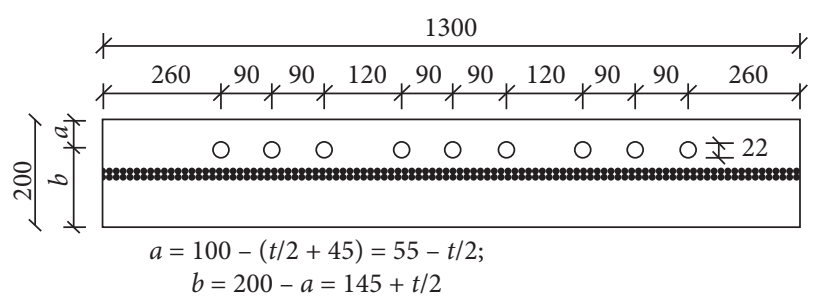

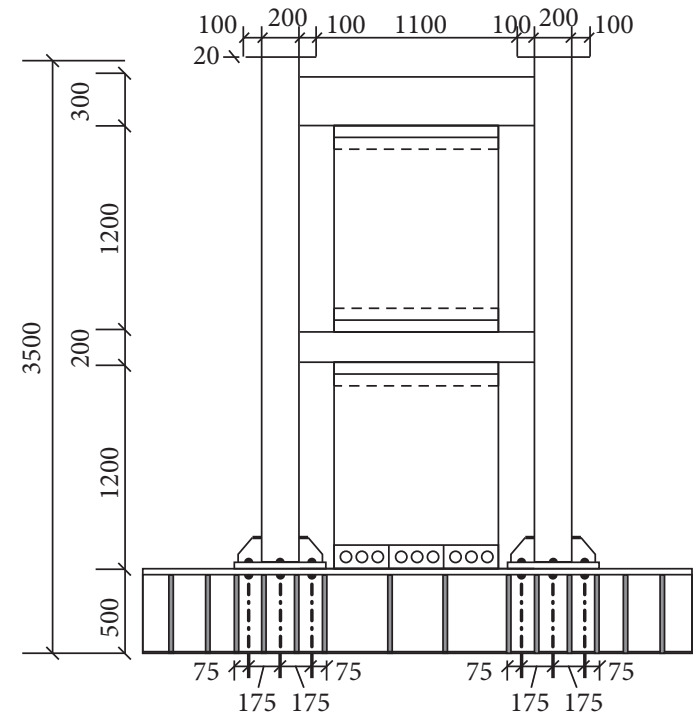

(b)

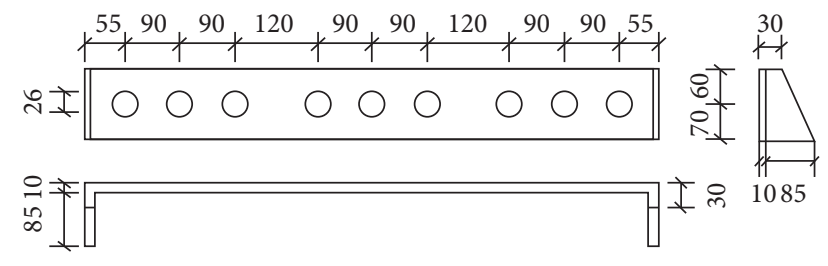

(d)

FIgURE 3: Continued. 


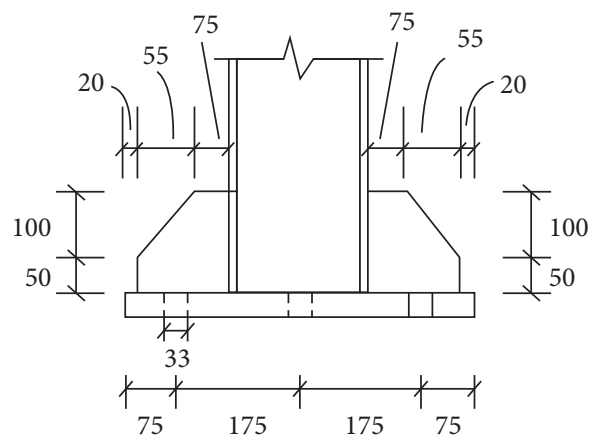

(e)
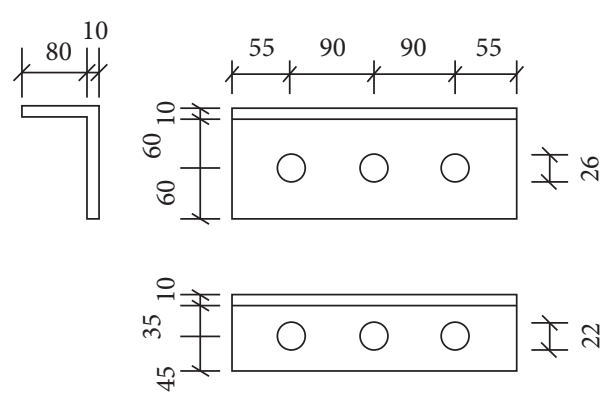

(f)

Figure 3: Detailed drawing of specimen processing. (a) Specimen A. (b) Specimen B. (c) Beam flange opening. (d) Connecting floor. (e) Column base. (f) Connecting cover plate.

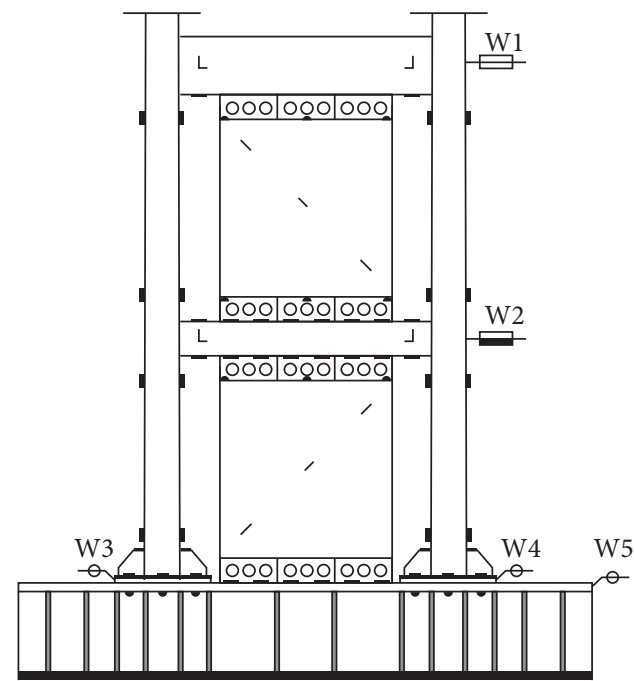

(a)

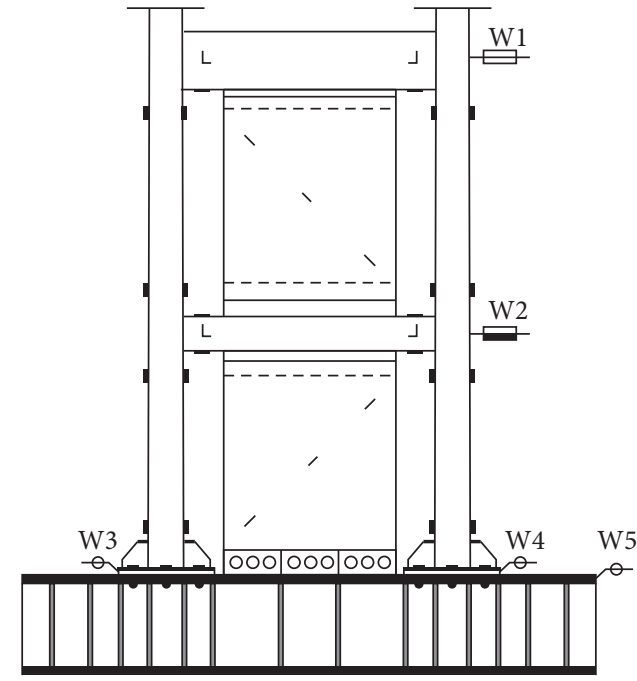

(b)

FIgURE 4: Layout of measuring points for displacement and strain of specimens. (a) Specimen A. (b) Specimen B.

both ends of the ground beam to resist the overall overturning moment and to achieve the fixed end restraint at the bottom of the plane frame. The horizontal top beam is used at both ends of the ground beam to prevent the rigid body displacement of the specimen in the plane. In order to prevent the ground beam from sliding during the loading process, the end restraint shall be checked and the bolts shall be tightened from time to time during the test loading process. Vertical load is provided by two vertical loading systems, which are composed of hydraulic jack, reaction frame, and rolling guide. A spherical hinge is set between the column jack and the jack to realize the free rotation of the column jack. A sliding roller trough is set between the column jack and the steel beam of the reaction frame to realize the sliding of the jack together with the column jack and ensure that the column jack always provides vertical load. In order to avoid out-of-plane instability of the test specimen during loading, a lateral support system is set up, which consists of a portal frame and a beam supported on the portal frame. Each floor is provided with a lateral brace, and the lower floor is arranged in the frame beam position.
However, in order to avoid the horizontal jack and ensure that the horizontal jack has enough loading space, the lateral support of the upper floor is arranged below the top beam.

3.2.3. Loading System. According to the American AISC seismic code [14], this test adopts a displacement-controlled loading mode and takes the interstory displacement angle as the controlling factor, as shown in Figure 5.

Firstly, the axial pressure is applied on the top of the column and the axial pressure ratio of the column is 0.3 . After successful loading under axial compression, the anchor bolts and frame column foot bolts are tightened again to eliminate the influence of the anchor bolts, the ground flatness, and the bottom flatness of the specimens on the test and to check whether the test device and the measuring equipment are working properly. Unload the jack on the top of the column, rebalance the acquisition system, and prepare for official loading. A predetermined axial load is applied to the top of the column, and the axial load is adjusted during the whole test process to ensure that the axial load is basically 


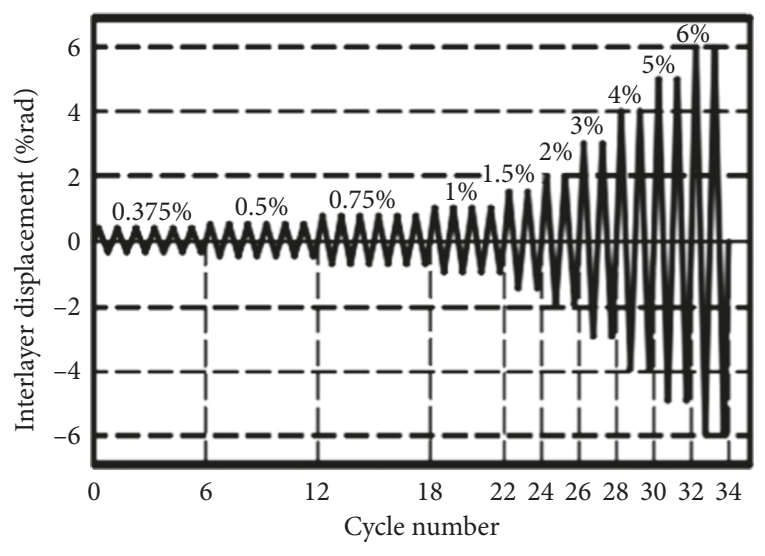

FIGURE 5: Loading protocol.

constant during the whole test process. Lower cyclic loads are applied at the end of the top beam, and the number of cycles and the corresponding interstory displacement angle of each stage load are shown in Figure 5.

\subsection{Test Phenomena}

3.3.1. Specimen B. According to the test scheme of specimen $\mathrm{B}, 640 \mathrm{kN}$ vertical loads were applied on the top of the two columns, respectively. After checking the normal operation of each instrument, it entered the horizontal loading stage. After the column is loaded, the maximum initial out-ofplane deflection of the measured steel plate is about $3 \mathrm{~mm}$.

When the specimen is loaded to $0.375 \%$ of the interlaminar displacement, there is a little out-of-plane buckling deformation on the basis of the initial imperfection in one floor of steel plate and no obvious change in other parts. When the interstory displacement reaches $0.5 \%$, the buckling of one-story embedded wallboard increases obviously and the drum sound appears in the process of pushpull alternation. When the interlaminar displacement reaches $0.75 \%$, the buckling of the first floor of the embedded steel plate continues to increase. Under the action of the main tensile stress, the steel plate forms an obvious tension band along the diagonal direction of the steel plate, as shown in Figure 6(a), while the second floor of the embedded steel plate also begins to buckle. When the interstory displacement reaches $1 \%$, the tension band of the two-floor wallboard begins to form, as shown in Figure 6(b); the out-ofplane buckling of the embedded wallboard becomes more and more serious, but the waveform remains unchanged; at this time, there is no obvious deformation in other parts of the specimen; and there is no obvious bolt slip in the discontinuous cover-plate connection joints connected with the ground beam.

When the interfloor displacement is loaded to $1.5 \%$, the wall slips slightly at the corner bolts connected with the ground beam; cracks appear on the eastern side of the weld between the first wall plate and the fishtail plate, as shown in the Figure 7(a), which shows that there is no obvious deformation of the frame beam at this time. When the specimens are loaded to the second circle of $2 \%$ interstory displacement, the bending deformation of the two-floor frame beams begins to be visible to the naked eye, and that of the first-floor frame beams begins to bend, but the deformation pattern is different from that of the second-floor frame beams. The buckling deformation is shown in Figure 7(c), while the top beam is only equipped with the embedded wallboard in the lower floor, so U-shaped bending deformation will be formed during hysteretic loading, as shown in Figure 7(c). The buckling sound of the wallboard increases with the increase of out-of-plane buckling when push-pull alternates.

When the specimen is loaded to $4 \%$ of the interfloor displacement, the out-of-plane buckling of the wallboard is very serious, first floor of the wallboard begins to appear cracks caused by the alternating tension bands of the wallboard, as shown in Figure 7(b). The welded joints between beams and columns are not damaged, and the bending failure of the top beam is serious, as shown in Figure 7(e), but the deformation of the first floor of the frame beam is much smaller than that of the top beam, as shown in Figure $7(d)$. The displacement of the load level has exceeded the maximum distance of the rolling guide between the vertical jack and the reaction frame and the test is stopped.

3.3.2. Specimen A. In accordance with the requirements of JGJ 82-2011 of “Technical Regulations for High Strength Bolt Connection of Steel Structures" [15], the final bolt of specimen $A$ is screwed after the axial force of the column is applied and a torque wrench is used to make the bolt reach the pretightening force specified in the design. After the final tightening is completed, the maximum initial deflection outside the steel plate surface measured is less than $2 \mathrm{~mm}$.

When the specimen is loaded to $0.375 \%$ of the interlaminar displacement, there is a little out-of-plane buckling deformation on the basis of the initial imperfection in one floor of the steel plate and no obvious change in other parts. When the interstory displacement reaches $0.5 \%$, the buckling of one-story embedded wallboard increases obviously and the drum sound appears in the process of pushpull alternation, which shows that in the first two loading stages, the experimental phenomena of specimen $\mathrm{A}$ and specimen B are almost the same and only slightly different in the wall plate buckling waveform. When the interstory displacement reaches $0.75 \%$, the buckling of one-story embedded wallboard continues to develop and the tension band begins to form. It can be seen from the mark of the corner of the lower-story embedded steel plate that the embedded steel plate is at the corner and the bolt slipped slightly. When the interstory displacement reaches $1 \%$, the tension band of the two-floor built-in wallboard also appears obviously; at the corner bolt of the first floor, the wallboard sliding continues to develop and the frame beam begins to show small deformation visible to the naked eye.

When the specimen is loaded to $1.5 \%$ of the interstory displacement, the embedded wallboard on the second floor begins to slip at the corner bolts connected with the middle beam and the deformation of the frame beam is also developing continuously. After loading $2 \%$ of the interstory 


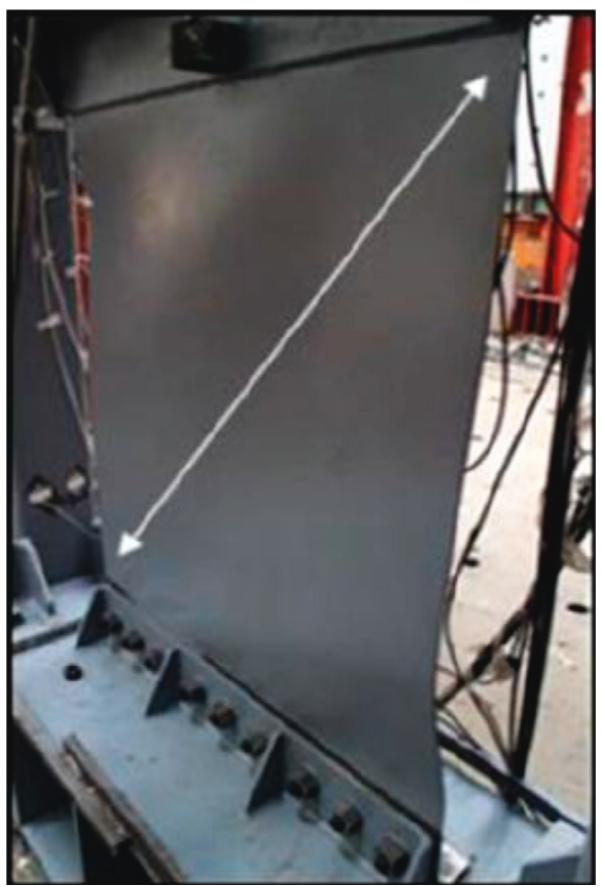

(a)

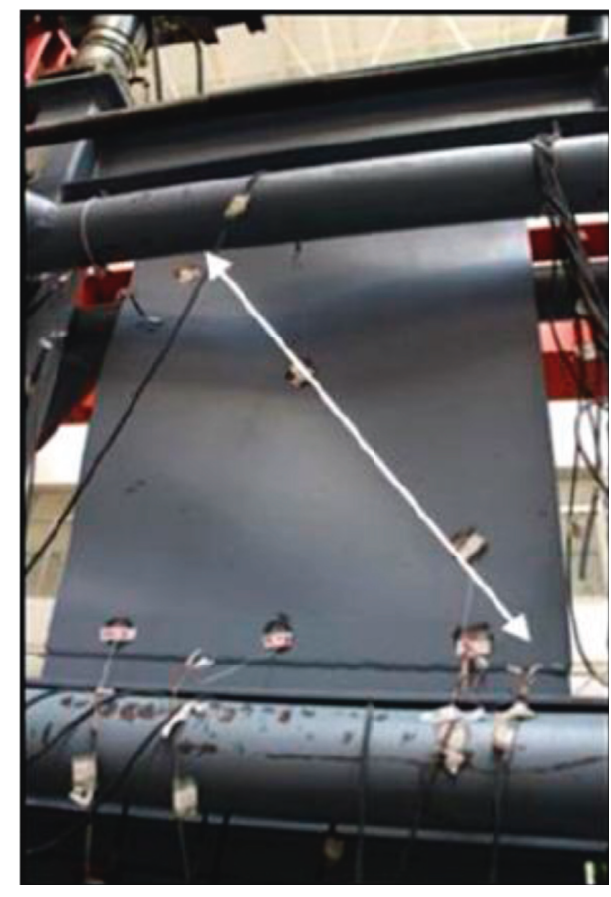

(b)

Figure 6: Tension field of specimen B. (a) Interfloor displacement of 0.75\%. (b) Interfloor displacement of $1 \%$.

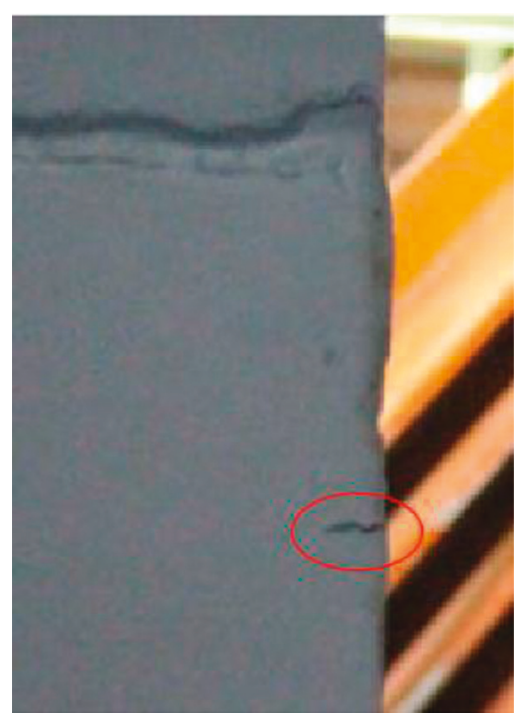

(a)

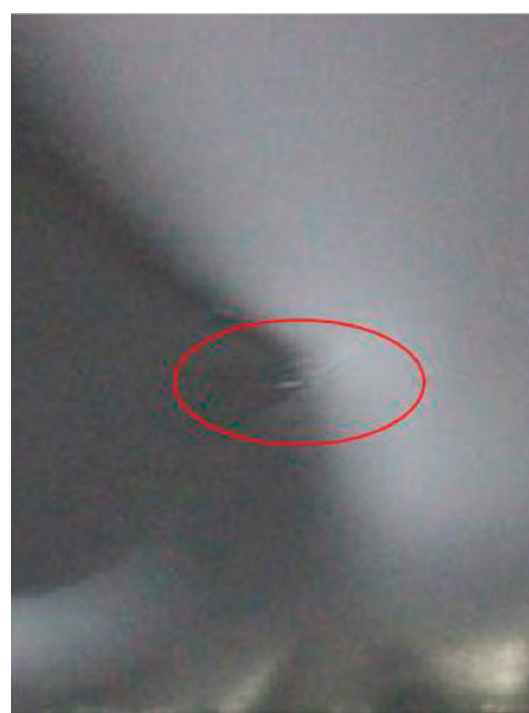

(b)

FIgUre 7: Continued. 


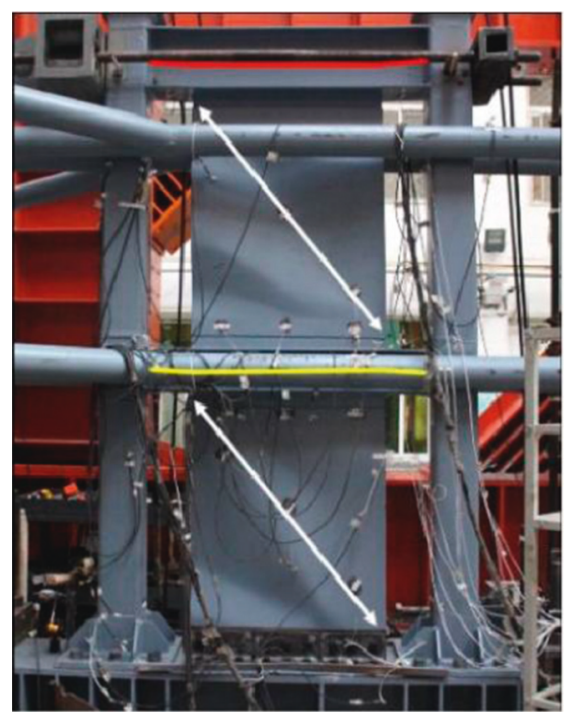

(c)

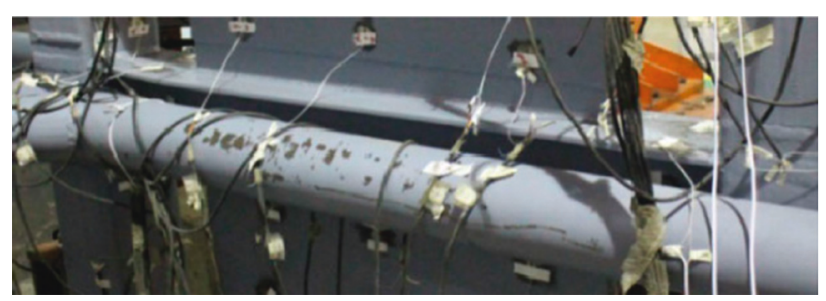

(d)

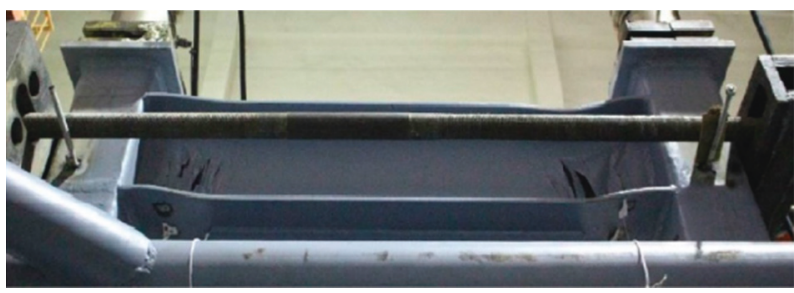

(e)

Figure 7: Failure characteristics of specimen B. (a) Weld crack. (b) Plate tear. (c) Global deformation. (d) Deformation of beam on first floor. (e) Deformation of frame top beam.

displacement, the inverted Z-shaped bending deformation of the frame beam of specimen $\mathrm{A}$ is similar to that of specimen $B$ and the U-shaped bending deformation of the top beam is similar, as shown in Figure 8(a). When push-pull alternates, the drum sound of the wall panel increases with the increase of out-of-plane buckling. When the specimen is loaded to $3 \%$ of the interstory displacement, the corner slip is quite serious, as shown in Figure 8(d), but there is no relative displacement between the connecting cover plate and the frame beam; the deformation of the frame beam is getting larger and larger, and the paint skin of the web of the frame beam begins to fall off; there is no obvious out-of-plane deformation between the connecting cover plate and the bottom plate at the joint of the embedded wall plate. When the specimen is loaded to $4 \%$ of the interstory displacement, there are no cracks similar to specimen B in the embedded steel plates of the two floors of the specimen; the welded joints between the beam and the column are not damaged, and the bending failure of the top beam is serious, as shown in Figure 8(b), but the deformation of the first-floor frame beam is much smaller than that of the top beam, as shown in Figure 8(c). Because the displacement of the next loading stage has exceeded the maximum distance of the rolling guide between the vertical jack and the reaction frame, in order to ensure safety, the test stopped.

DCPC joints are strengthened by the angle steel cover plate; the test results show that the high-strength bolt connection on the steel beam is almost perfect after the test, and there is no obvious deformation in the connection area between the steel beam and the embedded wallboard. On the contrary, the plastic bending deformation of the steel beam in the unconnected area is obvious. From the final deformation morphology of the specimens, it can be seen that the two groups of specimens have similar deformation of frame beams, but the final deformation range of specimen A frame beams is smaller than that of 


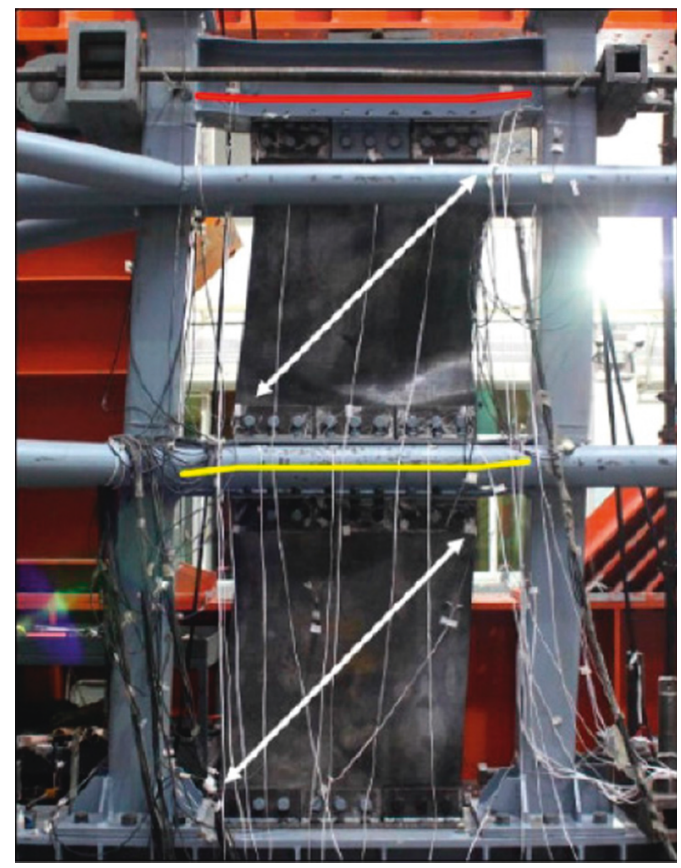

(a)

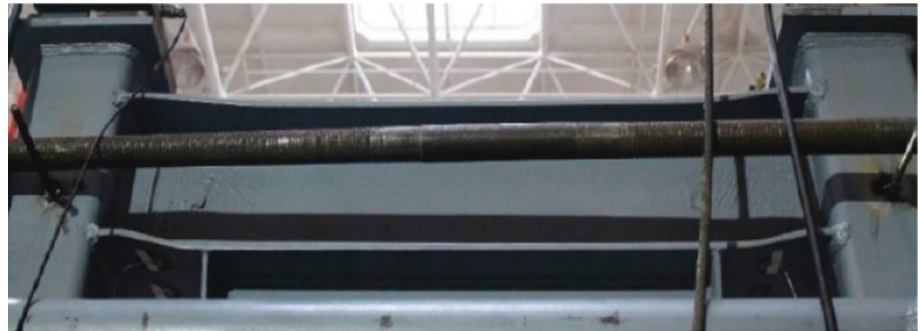

(b)

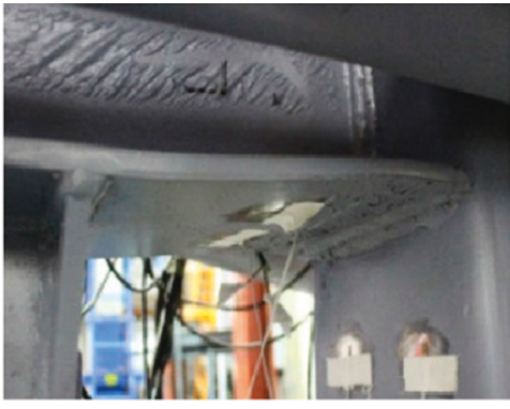

(c)

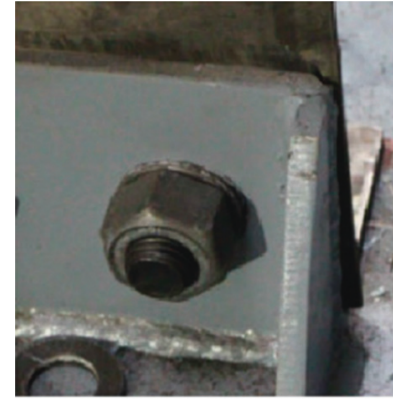

(d)

Figure 8: Failure characteristics of specimen A. (a) Specimen deformation. (b) Deformation of frame top beam. (c) Deformation of beam on first floor. (d) Slip of connection angle bolt.

specimen B. It is proved that the DCPC joint can ensure good load transfer performance of the steel plate shear wall connection area.

\section{Test Results and Analysis}

4.1. Hysteresis Curve. Hysteretic curve is the load-displacement curve of specimens under low-cycle reciprocating loads, which comprehensively reflects the rate of deterioration under cyclic loading and is also the main basis for the elastic-plastic dynamic response of the structure [16]. The load-displacement hysteresis curves of the two specimens are shown in Figure 9.

When the actuator is pushed to the west column, the displacement of the structure is greater than zero, which is called positive loading; when the actuator is pulled to the east column, the displacement of the structure is less than zero, which is called reverse loading. Figure 9 shows that the reading of the column top displacement meter is $110 \mathrm{~mm}$ and the whole vertex displacement angle is $1 / 25$ at the end of 


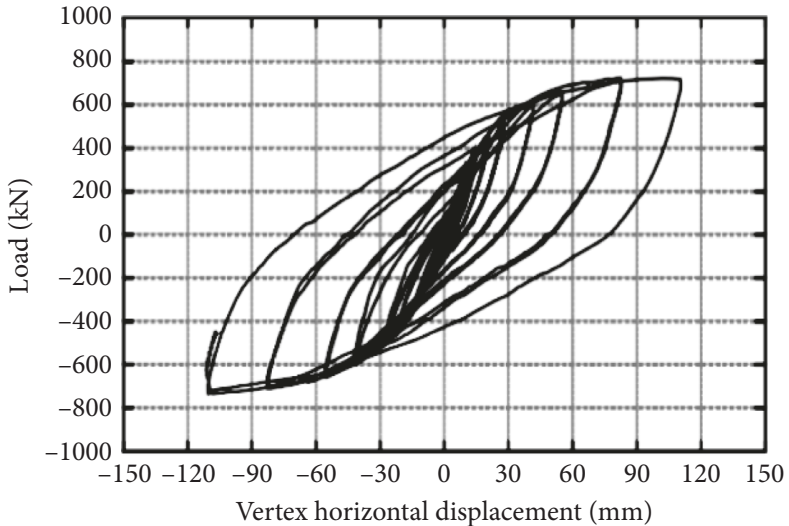

(a)

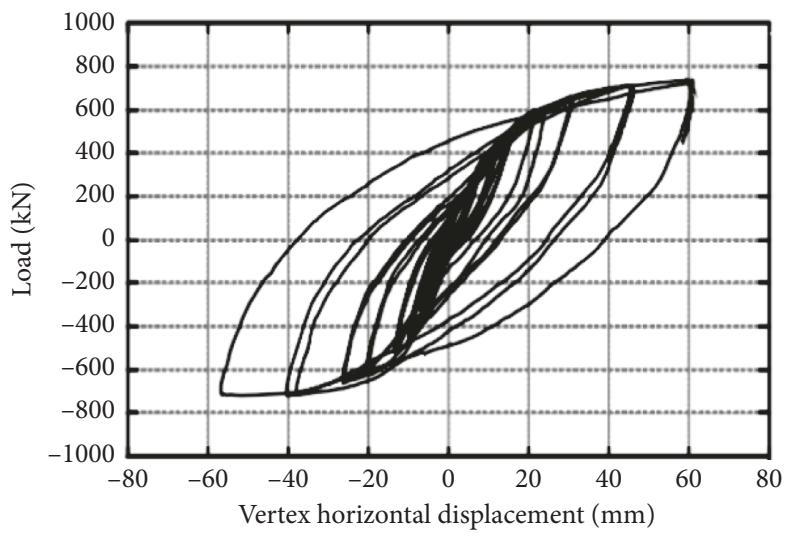

(c)

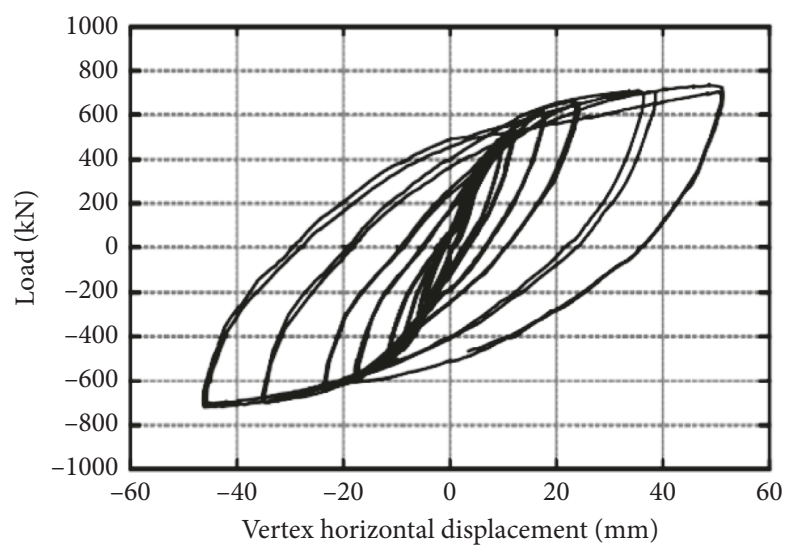

(e)

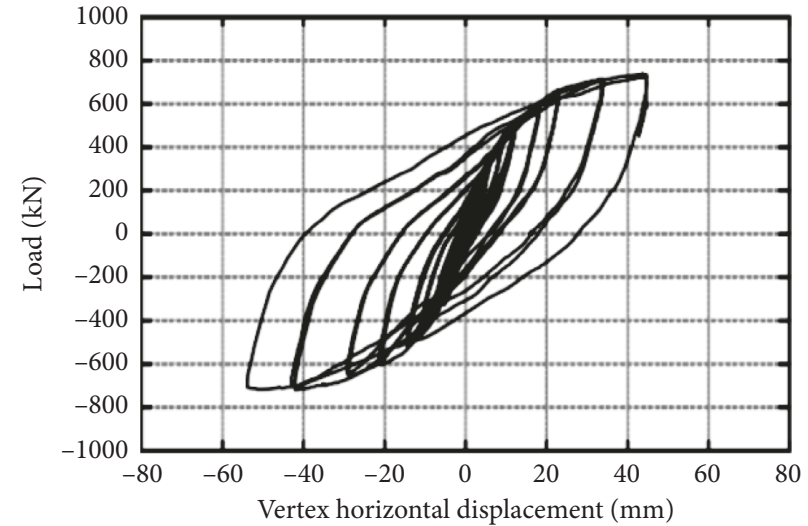

(b)

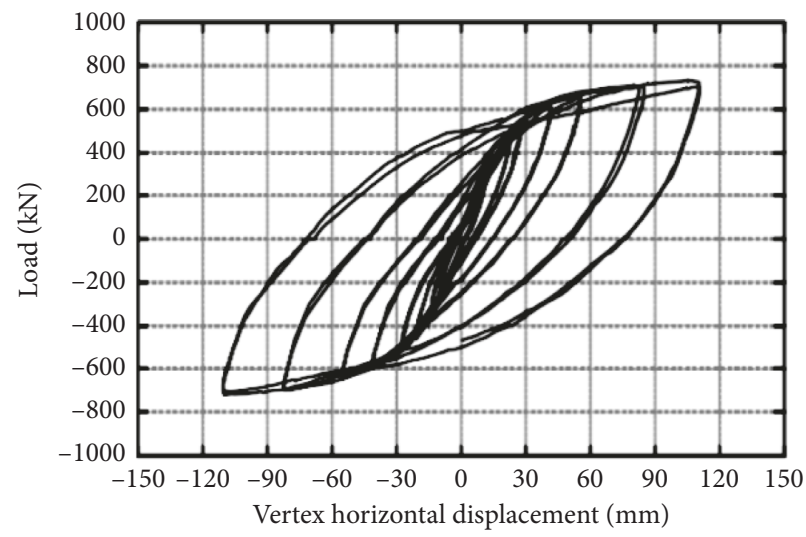

(d)

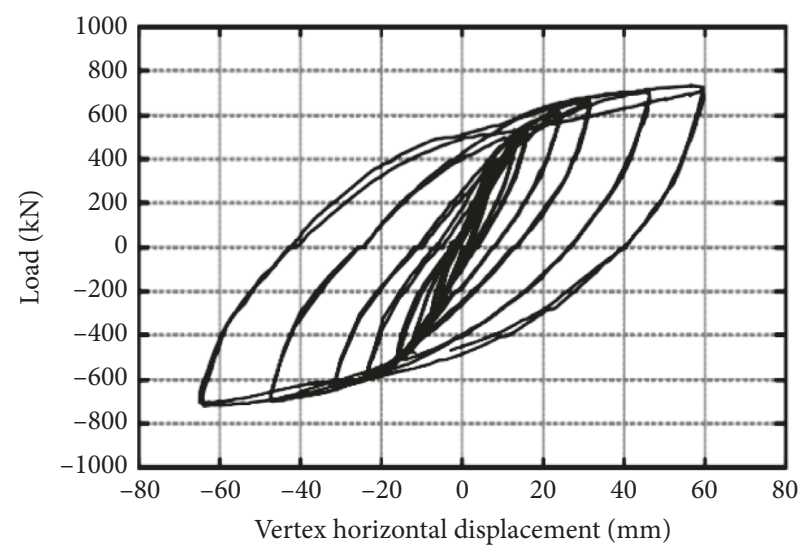

(f)

Figure 9: Hysteretic curves. (a) Global of specimen B. (b) First floor of specimen B. (c) Second floor of specimen B. (d) Global of specimen A. (e) First floor of specimen A. (f) Second floor of specimen A.

the test. The hysteresis curve shows the following characteristics.

Compared with Figures 9(a) and 9(d), the force and displacement of the two specimens are basically linear at the elastic stage, the hysteretic loop encloses a small area, and the unloading stiffness of the specimens is basically the same as the elastic stiffness. After the specimen yields, the out-of-plane buckling deformation of the embedded wallboard increases continuously, the tension band develops continuously, and the plastic part of the specimen increases gradually. After that, the hysteresis loops of the specimens gradually expand, the envelope area of the ring increases, and the stiffness of each loading stage begins to degenerate. With the increase of loading times, the unloading stiffness decreases slightly compared with the elastic stiffness. When the horizontal load is unloaded to zero, the residual displacement of the specimen increases with the increase of the loading stage. The hysteretic loops 


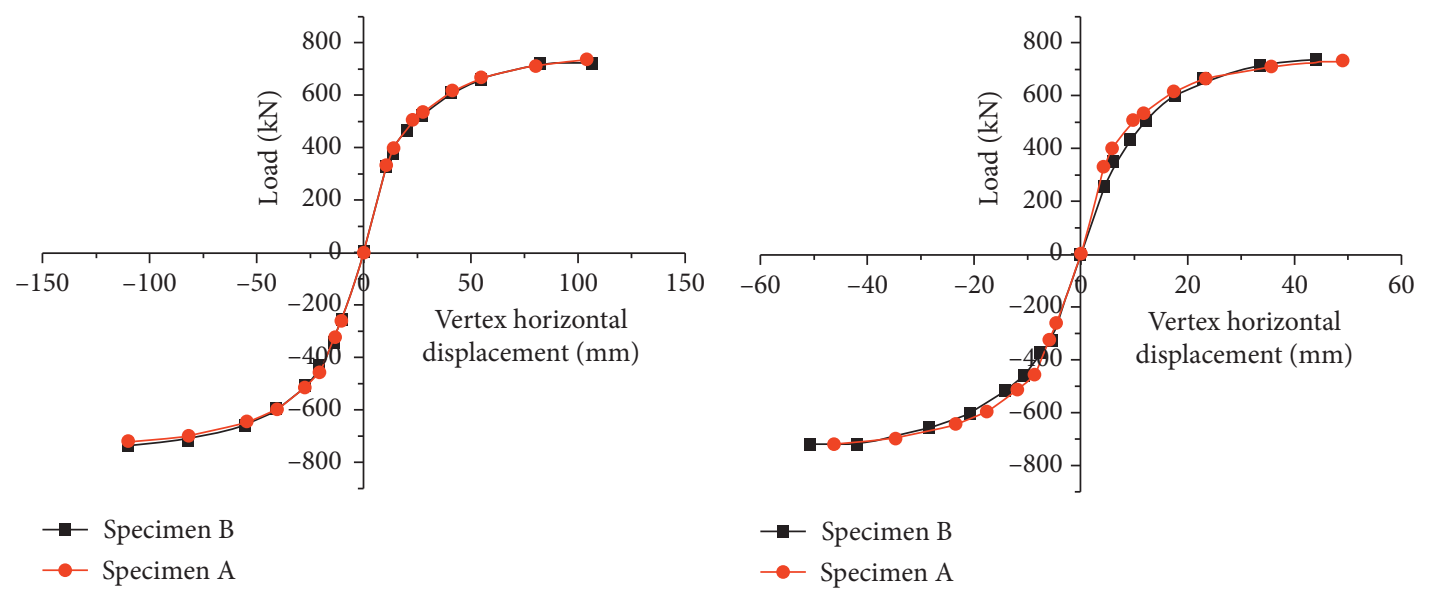

(a)

(b)

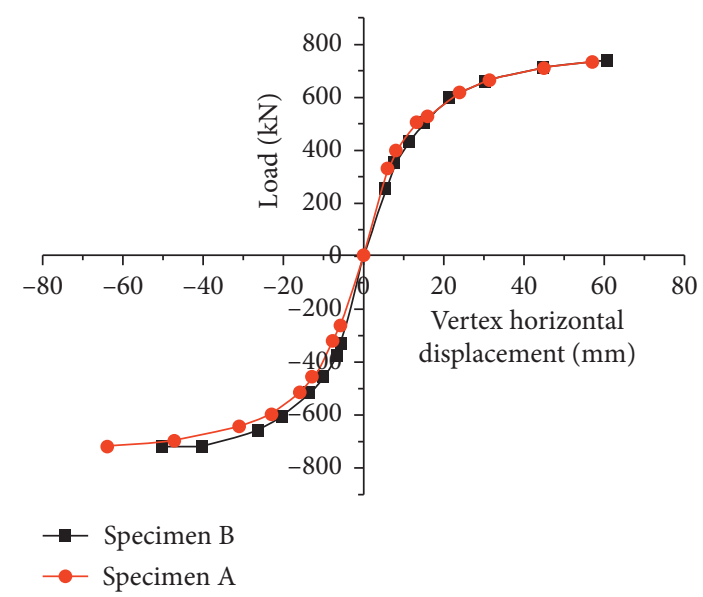

(c)

Figure 10: Skeleton curves of the specimen. (a) Whole. (b) First floor. (c) Second floor.

of the two specimens were not pinched, but the specimen $\mathrm{A}$ was fuller.

From Figures 9(b) and 9(c), it can be seen that from the seventh loading stage, the load-displacement curve on the first floor of specimen B appears asymmetric; under the same horizontal load, the negative interfloor displacement of the first floor is obviously larger than that of the square interfloor displacement. This is due to the tearing of the welding seam of a wall plate connection at this time, which results in the partial failure of the tension band of the negative direction steel plate, thus causing the stiffness asymmetry in the positive and negative directions of the specimen. However, the bearing capacity of the structure did not decrease sharply because of cracks, which indicates that the embedded wall panel has a higher degree of affluence. Up to the end of loading, there was no crack in the second floor of weld, so the hysteretic curve of the second floor was symmetrical. In the later stage of loading, because the top beam is only affected by the tension band of the unilateral embedded wall panel, the two-floor stiffness degenerates rapidly; the upper and lower tension bands of the middle beam can offset each other, the deformation of the first-floor beam is obviously smaller than that of the secondfloor top beam, and the stiffness degeneration is slower than that of the first-floor beam, so the displacement of the first floor is gradually smaller than that of the second floor after loading. As can be seen from Figures 9(e) and 9(f), the first and second hysteretic curves of specimen A with DCPC node are full and symmetrical. By comparison with Figures 9(b) and $9(\mathrm{c})$, the hysteretic curves of each floor of the two specimens are in good agreement.

4.2. Skeleton Curve and Ductility. From Figure 10(a), the overall skeleton curves of the two specimens basically coincide, which shows that the seismic performance of the steel plate shear wall with DPCP joint on both sides is almost the same as that of the traditional steel plate shear wall with welding on both sides.

Figures $10(\mathrm{~b})$ and $10(\mathrm{c})$ are the contrast diagrams of the skeleton curves of the first and second floors of the two specimens, respectively. By comparison, the skeleton curves of each floor of the two specimens are also in good agreement. Because of cracks in the first floor of specimen $B$ joint weld during loading, the positive and negative directions of the first-floor skeleton curve of the specimen are asymmetrical. However, due to the high 
TABLE 3: Test results of specimen B.

\begin{tabular}{|c|c|c|c|c|c|c|c|c|c|c|c|c|}
\hline \multirow[b]{2}{*}{$\begin{array}{l}\text { Floor } \\
\text { number }\end{array}$} & \multirow[b]{2}{*}{$\begin{array}{l}\text { Loading } \\
\text { direction }\end{array}$} & \multirow[b]{2}{*}{$\begin{array}{c}K_{i}(\mathrm{kN} / \\
\mathrm{mm})\end{array}$} & \multicolumn{3}{|c|}{ Yield } & \multicolumn{3}{|c|}{ Peak } & \multicolumn{3}{|c|}{ Limit } & \multirow[b]{2}{*}{$\begin{array}{c}\text { Displacement ductility } \\
\text { coefficient }\end{array}$} \\
\hline & & & $\begin{array}{c}P y \\
(\mathrm{kN})\end{array}$ & $\begin{array}{c}\Delta y \\
(\mathrm{~mm})\end{array}$ & $\begin{array}{c}\Delta y / h \\
(\%)\end{array}$ & $\begin{array}{c}P m \\
(\mathrm{kN})\end{array}$ & $\begin{array}{c}\Delta m \\
(\mathrm{~mm})\end{array}$ & $\begin{array}{c}\Delta m / h \\
(\%)\end{array}$ & $\begin{array}{c}P u \\
(\mathrm{kN})\end{array}$ & $\begin{array}{c}\Delta u \\
(\mathrm{~mm})\end{array}$ & $\begin{array}{c}\Delta u / h \\
(\%)\end{array}$ & \\
\hline \multirow[b]{2}{*}{ Global } & $\begin{array}{c}\text { Pull } \\
\text { direction }\end{array}$ & 25.1 & 346.6 & 13.75 & 0.50 & 736.75 & 110.24 & 4.01 & 736.75 & 110.24 & 4.01 & 8.02 \\
\hline & $\begin{array}{c}\text { Push } \\
\text { direction }\end{array}$ & 30.3 & 376.08 & 13.78 & 0.50 & 720.44 & 82.39 & 3.00 & 718.32 & 106.69 & 3.88 & 7.74 \\
\hline \multirow{2}{*}{ First floor } & $\begin{array}{c}\text { Pull } \\
\text { direction }\end{array}$ & 57.3 & 346.17 & 6.14 & 0.47 & 736.13 & 43.90 & 3.38 & 736.13 & 43.90 & 3.38 & 7.15 \\
\hline & $\begin{array}{c}\text { Push } \\
\text { direction }\end{array}$ & 62.3 & 377.44 & 7.69 & 0.59 & 720.44 & 41.96 & 3.23 & 719.54 & 50.82 & 3.91 & 6.61 \\
\hline \multirow{2}{*}{$\begin{array}{l}\text { Second } \\
\text { floor }\end{array}$} & $\begin{array}{c}\text { Pull } \\
\text { direction }\end{array}$ & 44.2 & 345.39 & 7.68 & 0.53 & 736.75 & 60.84 & 4.20 & 736.75 & 60.84 & 4.20 & 7.92 \\
\hline & $\begin{array}{c}\text { Push } \\
\text { direction }\end{array}$ & 61.2 & 377.60 & 6.51 & 0.45 & 719.54 & 40.26 & 2.78 & 719.08 & 50.20 & 3.46 & 7.72 \\
\hline
\end{tabular}

TABLE 4: Test results of specimen A.

\begin{tabular}{|c|c|c|c|c|c|c|c|c|c|c|c|c|}
\hline \multirow[b]{2}{*}{$\begin{array}{l}\text { Floor } \\
\text { number }\end{array}$} & \multirow[b]{2}{*}{$\begin{array}{l}\text { Loading } \\
\text { direction }\end{array}$} & \multirow[b]{2}{*}{$\begin{array}{c}K_{i}(\mathrm{kN} / \\
\mathrm{mm})\end{array}$} & \multicolumn{3}{|c|}{ Yield } & \multicolumn{3}{|c|}{ Peak } & \multicolumn{3}{|c|}{ Limit } & \multirow[b]{2}{*}{$\begin{array}{l}\text { Displacement ductility } \\
\text { coefficient }\end{array}$} \\
\hline & & & $\begin{array}{c}P y \\
(\mathrm{kN})\end{array}$ & $\begin{array}{c}\Delta y \\
(\mathrm{~mm})\end{array}$ & $\begin{array}{c}\Delta y / h \\
(\%)\end{array}$ & $\begin{array}{c}P m \\
(\mathrm{kN})\end{array}$ & $\begin{array}{c}\Delta m \\
(\mathrm{~mm})\end{array}$ & $\begin{array}{c}\Delta m / h \\
(\%)\end{array}$ & $\begin{array}{c}P u \\
(\mathrm{kN})\end{array}$ & $\begin{array}{c}\Delta u \\
(\mathrm{~mm})\end{array}$ & $\begin{array}{c}\Delta u / h \\
(\%)\end{array}$ & \\
\hline \multirow{2}{*}{ Global } & $\begin{array}{c}\text { Pull } \\
\text { direction }\end{array}$ & 25.2 & 321.71 & 13.64 & 0.50 & 719.54 & 110.13 & 4.00 & 719.54 & 110.13 & 4.00 & 8.07 \\
\hline & $\begin{array}{c}\text { Push } \\
\text { direction }\end{array}$ & 31.8 & 396.92 & 13.79 & 0.50 & 732.22 & 104.46 & 3.80 & 732.22 & 104.46 & 3.80 & 7.58 \\
\hline \multirow{2}{*}{ First floor } & $\begin{array}{c}\text { Pull } \\
\text { direction }\end{array}$ & 57.1 & 321.71 & 5.96 & 0.46 & 719.54 & 46.13 & 3.55 & 719.54 & 46.13 & 3.55 & 7.74 \\
\hline & $\begin{array}{c}\text { Push } \\
\text { direction }\end{array}$ & 75.4 & 397.38 & 5.75 & 0.44 & 732.22 & 49.03 & 3.77 & 732.22 & 49.03 & 3.77 & 8.53 \\
\hline \multirow{2}{*}{$\begin{array}{l}\text { Second } \\
\text { floor }\end{array}$} & $\begin{array}{c}\text { Pull } \\
\text { direction }\end{array}$ & 45.7 & 321.71 & 7.68 & 0.53 & 719.54 & 64.00 & 4.41 & 719.54 & 64.00 & 4.41 & 8.33 \\
\hline & $\begin{array}{c}\text { Push } \\
\text { direction }\end{array}$ & 55.1 & 396.92 & 8.02 & 0.55 & 732.22 & 57.09 & 3.94 & 732.22 & 57.09 & 3.94 & 7.12 \\
\hline
\end{tabular}

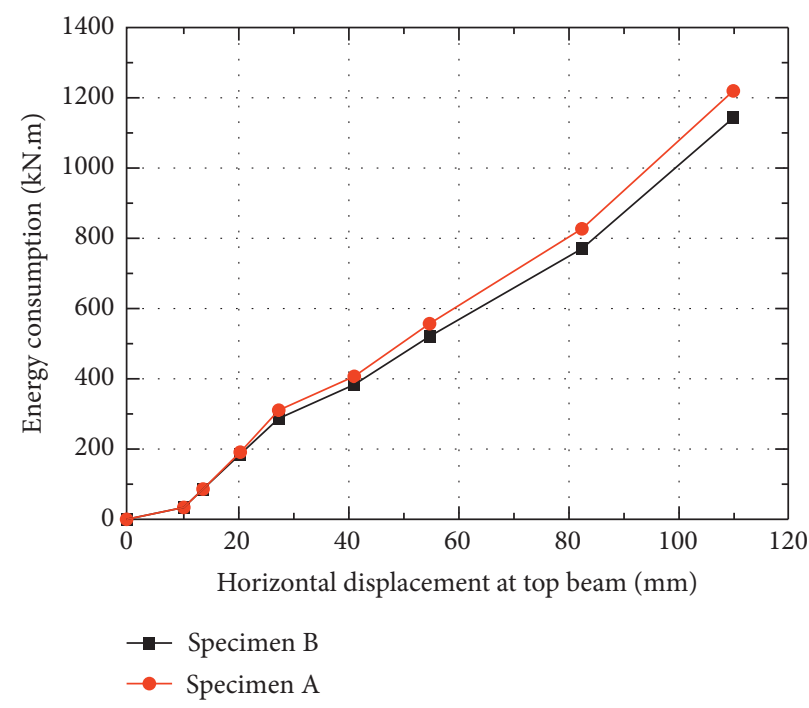

FIGURE 11: Energy dissipation capacity.

wealthiness of the built-in wallboard, cracks have no significant impact on the seismic performance of the whole structure.
The test results of specimen $\mathrm{B}$ and $\mathrm{A}$ are given in $\mathrm{Ta}-$ bles 3 and 4, respectively. By comparison, the initial stiffness of the two specimens is basically the same and the 


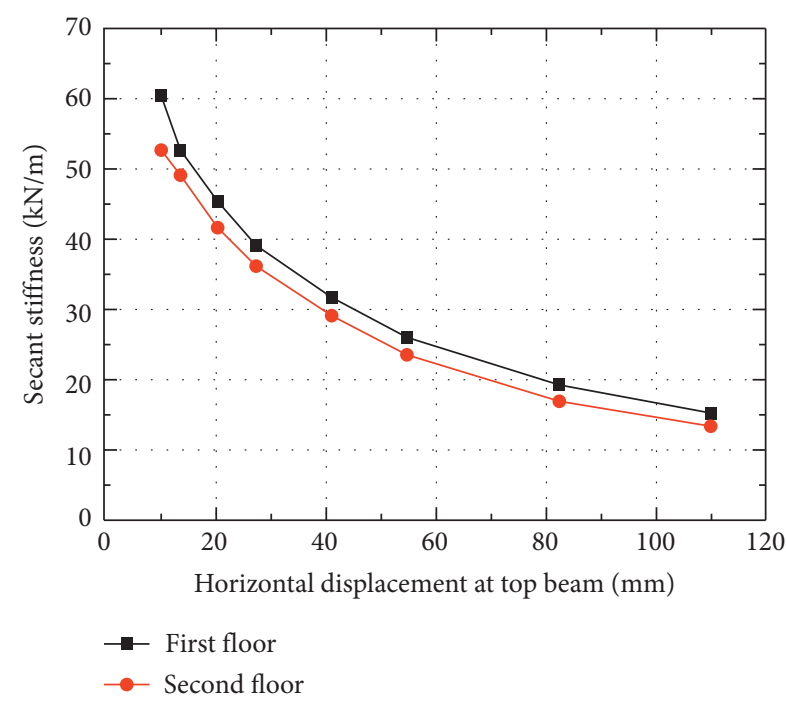

(a)

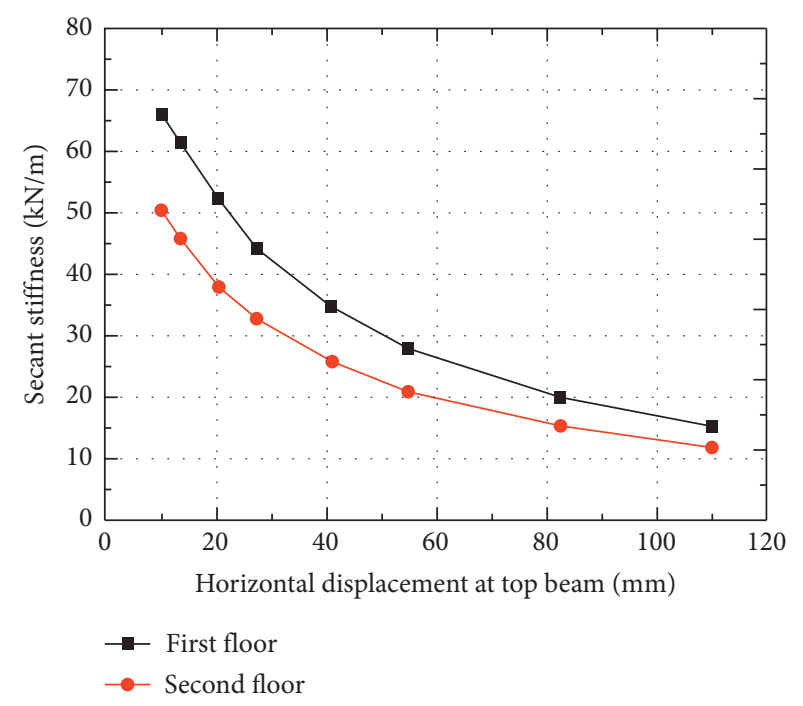

(b)

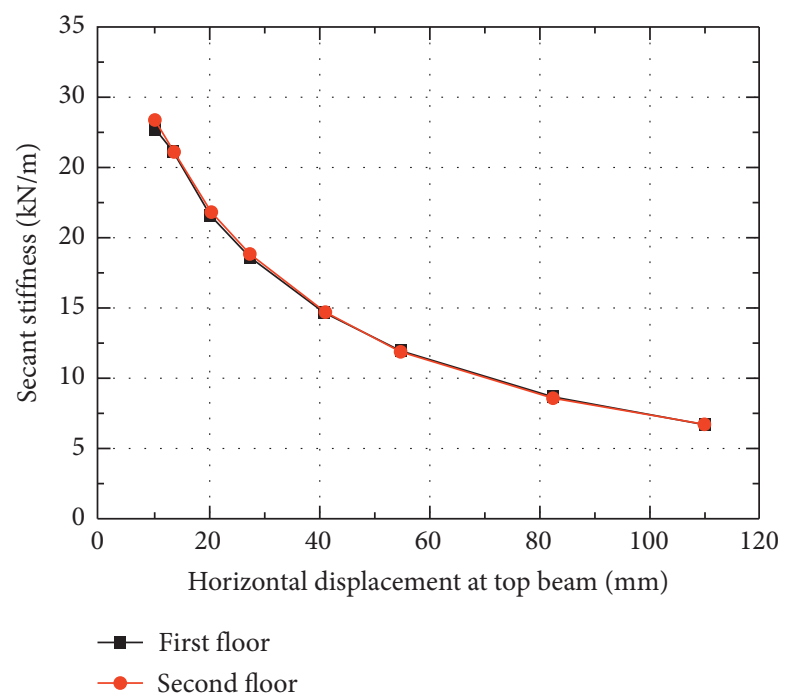

(c)

Figure 12: Stiffness degeneration. (a) Interlaminar stiffness of specimen B. (b) Interlaminar stiffness of specimen A. (c) Integral stiffness.

ductility coefficients of push and pull directions are about 8.0 , which proves that both groups of specimens have good ductility.

4.3. Energy Consumption Capacity. As can be seen from Figure 11, the energy consumption of the two specimens increases with the increase of displacement until the end of loading. In the first three loading stages, the energy consumption of the two specimens is low and almost the same. As the fourth loading stage enters, the energy consumption of the specimen A exceeds than that of the specimen $B$ and the gap increases with the increase of displacement. This is due to the large bolt holes in the embedded wallboard of specimen A. At the fourth loading stage, the wallboard begins to slip at the corner connecting bolts and the slip of the wallboard provides a part of energy dissipation. With the increase of displacement, the sliding area of wallboard increases with the development of tension band, so the energy consumption provided by sliding increases.

4.4. Stiffness Degradation. In order to understand the stiffness variation characteristics of specimens under reciprocating loads, the ratio of the sum of absolute values of load and displacement in two directions is taken as the secant stiffness of specimens at different stages to describe the stiffness degradation of specimens. The secant stiffness of the specimen is shown in Figure 12.

From Figure 12(a), it can be seen that the stiffness of the first floor of specimen $B$ is larger than that of the second floor, and it degenerates synchronously during loading. This is because the stiffening ribs are arranged at the foot of the first floor of the specimen, so the stiffness of the first floor is larger. From Figure 12(b), it can be seen that the 
stiffness of the first floor of specimen $\mathrm{A}$ is also larger than that of the second floor and the degradation rate of the stiffness of the first floor is faster than that of the second floor. This is because in the process of loading, the slip of one-story embedded wallboard at the corner connecting bolt is obviously larger than that of the second floor. Compared with Figures 12(a) and 12(b), the degradation rate of stiffness of specimen $A$ is faster in the initial stage of loading than that of specimen $B$, but slower in the later stage, which makes the final residual stiffness of each floor equal. Figure 12(c) shows the overall stiffness degradation curves of two specimens, and the two curves are in good agreement. The initial stiffness of specimen A is slightly higher than that of specimen $B$, which is due to the field assembly of specimen $\mathrm{A}$, and effectively reduces the initial defects that may occur in the transportation of the specimen.

\section{Conclusion}

Low cyclic loading tests were carried out on the welded steel frame-steel plate shear wall structure and assembled steel frame-steel plate shear wall structure with discontinuous cover-plate connections. The following conclusions are drawn:

(1) The assembled steel frame-steel plate shear wall structure with DCPC has full shuttle-shaped hysteretic curve, stable hysteretic performance, and good ductility.

(2) The assembled steel frame-steel plate shear wall structure with DCPC is connected on both sides, with the increase of displacement, the wallboard first buckles and forms a tension band. Thereafter, the additional bending moment caused by the tension band causes the bending failure of the frame beam. Up to the end of the test, there was no obvious damage to the frame column, which indicated that the structure itself conformed to the seismic design concept of "strong frame, weak wallboard, strong column, and weak beam."

(3) The seismic performance of the assembled steel frame-steel plate shear wall structure with DCPC is comparable to that of the welded steel frame-steel plate shear wall structure, and the energy dissipation capacity of the former is better than that of the latter.

(4) The bolt hole sliding energy dissipation is adopted in DCPC joints, which effectively protects the frame beam and ensures the integrity of the components in the joint area and provides good postearthquake repair function.

(5) The assembled steel plate shear wall with DCPC effectively reduces the number of connecting bolts and is easy to assemble and convenient for opening and stiffness adjustment.

\section{Data Availability}

The data used to support the findings of this study are available from the corresponding author upon request.

\section{Conflicts of Interest}

The authors declare that they have no conflicts of interest.

\section{Acknowledgments}

This work was supported by the National Key R\&D Program (2017YFC0701614).

\section{References}

[1] X. T. Wang, Z. Chao, G. Q. Jiang et al., "Experimental research on seismic behavior of concrete-filled square steel tubular column frame-thin steel plate shear walls with middle opening," Journal of Building Structures, vol. 36, no. 8, pp. 16-23, 2015.

[2] A. L. Zhang, X. Zhang, X. C. Liu et al., "Experimental study on seismic behavior of steel frame-fabricated thin steel plate shear wall with two sides connection," Engineering Mechanics, vol. 35, no. 9, pp. 54-63, 2018.

[3] Y. H. Wang, W. L. Cao, and G. Li, "The seismic behaviour of the materials used in the steel-plate shear walls with concrete filled steel tube columns," Advanced Materials Research, vol. 194-196, pp. 2014-2017, 2011.

[4] H.-S. Hu, J.-G. Nie, J.-S. Fan, M.-X. Tao, Y.-H. Wang, and S.-Y. Li, "Seismic behavior of CFST-enhanced steel platereinforced concrete shear walls," Journal of Constructional Steel Research, vol. 119, pp. 176-189, 2016.

[5] S.-Y. Seo, H.-D. Yun, and Y.-S. Chun, "Hysteretic behavior of conventionally reinforced concrete coupling beams in reinforced concrete coupled shear wall," International Journal of Concrete Structures and Materials, vol. 11, no. 4, pp. 599-616, 2017.

[6] H. B. Shim, J. H. Lee, and H. S. Park, "Shear force of headed shear studs, high-strength shear studs and steel plate embedded in concrete: an experimental study," Materials Research Innovations, vol. 19, no. sup8, pp. S8-S145, 2015.

[7] W. Hou, B. Chen, Z. Guo et al., "Experimental study on seismic behavior of embedded steel plate reinforced concrete coupling beams," China Civil Engineering Journal, vol. 50, no. 2, pp. 9-18, 2017.

[8] Y. Wu, D. Kang, L. Gao et al., "Seismic behavior of bolted endplate connection between steel reinforced concrete (SRC) wall and SRC beam for use in high-rise buildings," International Journal of Civil Engineering, vol. 16, no. 2, pp. 1-12, 2018.

[9] Y. Wu, J. Fu, Y.-B. Lan, T. au, and Y.-B Yang, "seismic performance of endplate connections between steel reinforced concrete walls and steel beams," Structural Engineering International, vol. 28, no. 2, pp. 208-217, 2018.

[10] F.-X. Ding, G.-A. Yin, L.-P. Wang, D. Hu, and G.-Q. Chen, "Seismic performance of a non-through-core concrete between concrete-filled steel tubular columns and reinforced concrete beams," Thin-Walled Structures, vol. 110, pp. 14-26, 2017.

[11] B. Rong, R. Liu, G. Feng, C. You, and F. Apostolos, "Flexural capacity formula of diaphragm-through joints of concretefilled square steel tubular columns," Transactions of Tianjin University, vol. 23, no. 3, pp. 258-266, 2017.

[12] M. A. Rusli, A. Murtopo, I. Siswanto, and M. F. Siswanto, "Full height rectangular opening castellated steel beam with diagonal stiffener," Applied Mechanics and Materials, vol. 881, pp. 150-157, 2018. 
[13] S. Karthika, P. Lakshimikandhan, and G. Dhinakaran, "Load deflection characteristics of sustainable infilled concrete wall panels," Arabian Journal for Science and Engineering, vol. 41, no. 2, pp. 451-460, 2016.

[14] N. Balasubramani and R. Thenmozhi, "Behaviour and strength of innovative steel concrete columns with SCC," Advanced Materials Research, vol. 984-985, pp. 684-692, 2014.

[15] JGJ 82-2011, Technical Specification for High Strength Bolt Connection of Steel structure, China Architecture\& Building Press, Beijing, China, 2011.

[16] K. Wang, S.-F. Yuan, Z.-X. Zhi, G.-L. Shi, and D.-F. Cao, "Experimental study on hysteretic behavior of composite frames with concrete-encased CFST columns," Journal of Constructional Steel Research, vol. 123, pp. 110-120, 2016. 


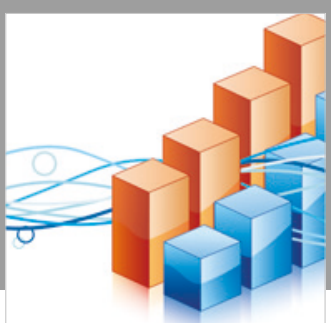

Advances in

Operations Research

\section{-n-m}
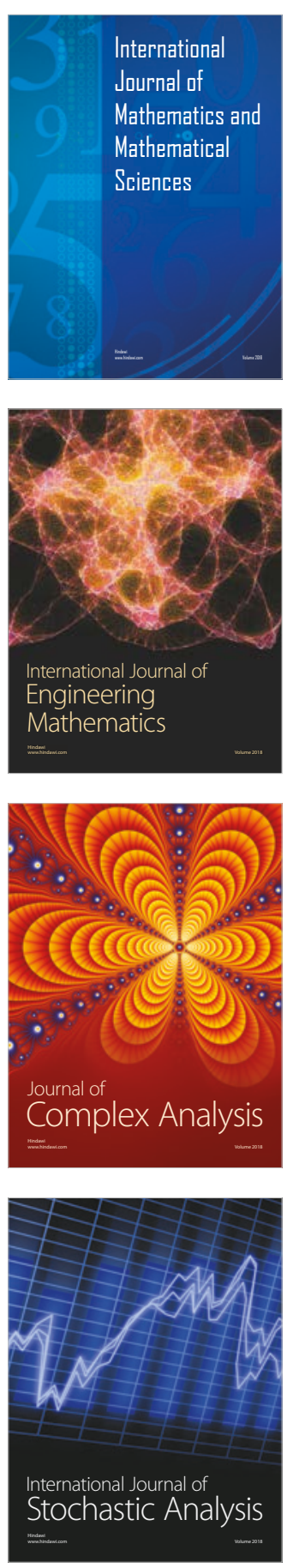
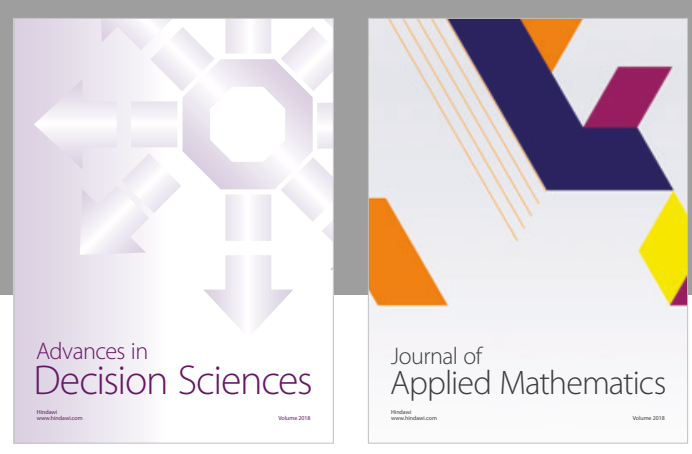

Journal of

Applied Mathematics
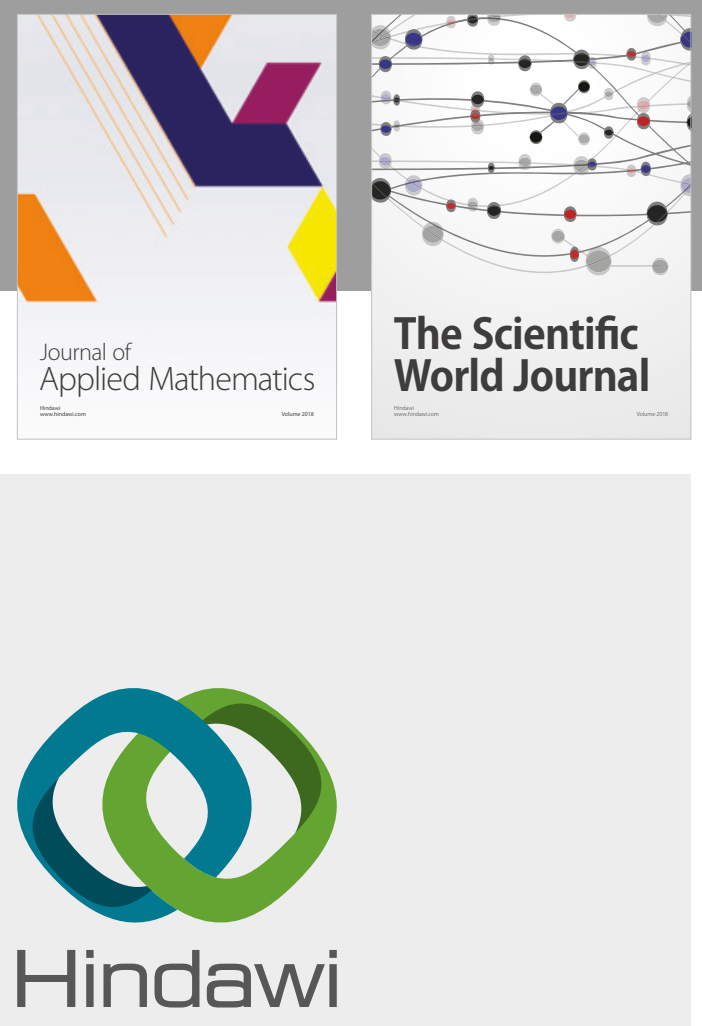

Submit your manuscripts at

www.hindawi.com

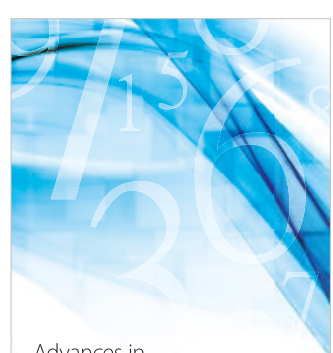

Advances in
Numerical Analysis
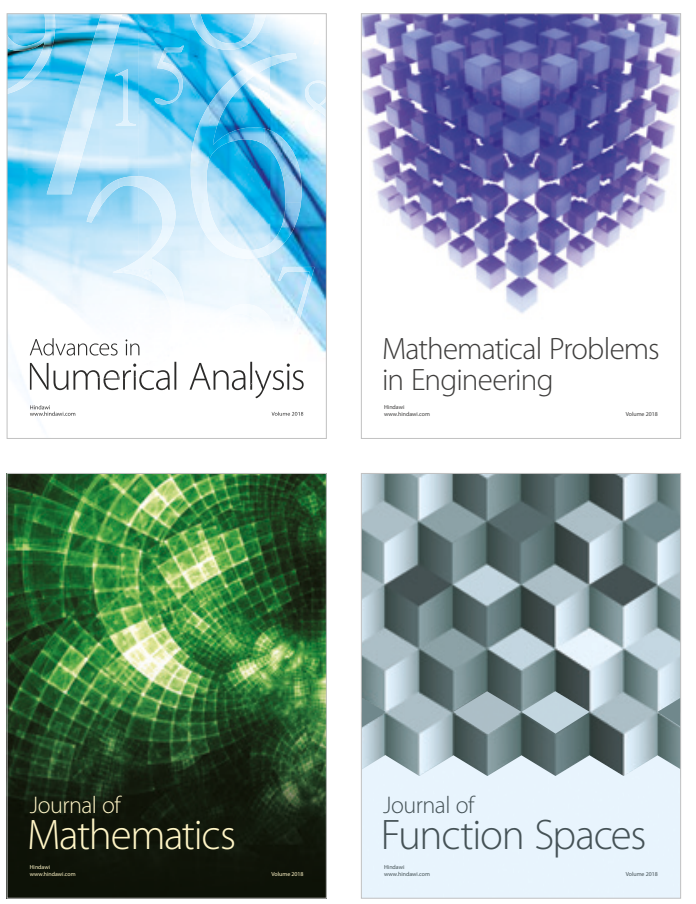

Mathematical Problems in Engineering

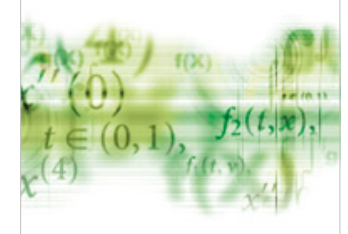

International Journal of

Differential Equations

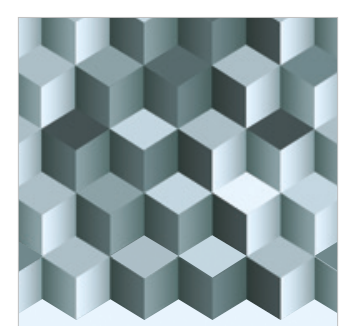

Journal of

Function Spaces

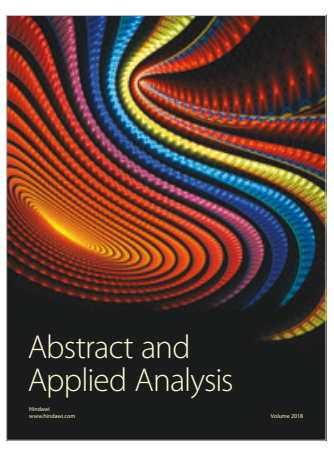

The Scientific

World Journal

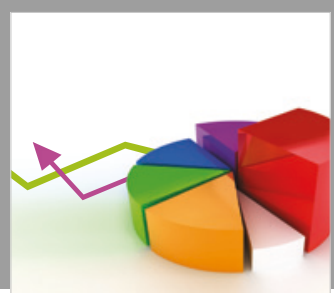

Journal of

Probability and Statistics
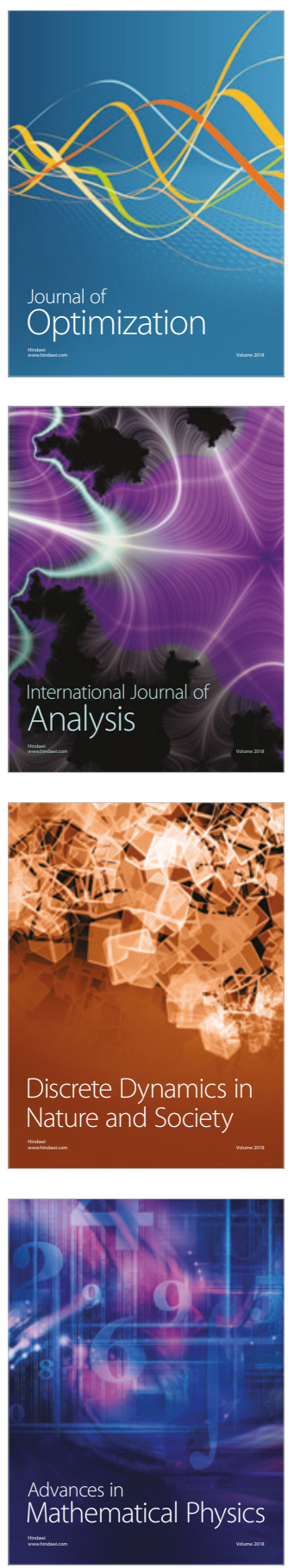